\title{
CORRESPONDENCE
}

We welcome letters to the Editor concerning articles which have recently been published. Such letters will be subject to the usual stages of selection and editing; where appropriate the authors of the original article will be offered the opportunity to reply.

Letters should normally be under $\mathbf{5 0 0}$ words in length, double-spaced throughout, signed by all authors and fully referenced. The edited version will be returned for approval before publication.

\section{TRAINING SPINAL SURGEONS}

Sir,

I read with great interest your recent editorial in the March 1992 issue on training spinal surgeons (1992;74-B:174-5). $\mathrm{Mr}$ Crockard is correct in his desire to see spinal surgery become a specialty practised by those who spend the majority of their time dealing with spinal diseases.

I am particularly encouraged to see an editorial from a neurosurgeon in an orthopaedic journal. It is fruitful to note that barriers are finally breaking down between the specialties of neurosurgery and orthopaedics.

Spinal surgery has become increasingly complex and although there have been great advances in the application of techniques based on improved understanding of biomechanics and imaging of the spine, few advances have been made in patient selection. As a result, more and more failed spinal surgery is being seen. Indeed, there are surgeons who deal with nothing else. The development of such prestigious societies as the North American Spine Society, Cervical Spine Research Society, and the International Society for the Study of the Lumbar Spine has encouraged the crossfertilisation between specialties.

No one, however, has yet addressed the training of the spinal surgeon. We are attempting to do this at Johns Hopkins University, and foresee a significant amount of time spent in orthopaedics by neurosurgical residents and vice versa. Six months' cross-training would be a start, but is a minimal exposure. What is more important is fellowship exchange; orthopaedic surgeons must be prepared to provide fellowships for neurosurgeons, and this is slowly evolving in the United States. One problem with fellowships is that many are not broad enough, and are sub-specialised to scoliosis, or trauma, or low back pain. On this basis, I feel that a registry of fellowships which is international in scope would allow a surgeon who wishes to devote his time to the spine to have access to a much broader range of experience.

Unfortunately, efforts to date have concentrated more on technique and not enough on the problems of pain and pain management. Of equal importance are the general rehabilitation of the patient undergoing spinal surgery and the management of the patient who is not a candidate for surgical intervention. Hopefully, this will improve. The Journal of Bone and Joint Surgery is to be congratulated on its editorial.

\section{J. P. KOSTUIK, MD}

Johns Hopkins Hospital

Baltimore

Maryland, USA.

(C) 1992 British Editorial Society of Bone and Joint Surgery $0301-620 X / 92 / 5457 \$ 2.00$

J Bone Joint Surg [ Br] 1992; 74-B :786-9.
Sir,

The editorial on the training of spinal surgeons by Mr Alan Crockard (1992;74-B:174-5) raises important questions. Specific interest groups in spinal surgery have developed over the last two decades in the United Kingdom and internationally, under the auspices of the British Orthopaedic Association, the British Scoliosis Society, the European Spinal Society and the International Society for the Study of the Lumbar Spine. Spinal work involves not only back pain and nerve root entrapment but spinal trauma and deformity as well as spinal tumour and scoliosis. The problems of the provision of services are compounded by the number of patients with back pain who are referred to surgeons, but do not require surgical treatment.

A spinal surgeon needs to be competent in all approaches to the spine, experienced in all forms of spinal fixation, able to deal with disc and stenosis problems, and be familiar with minimal intervention methods. He should also be able to treat adult spinal deformity and spondylolisthesis and major spinal trauma.

The current changes in higher specialist training in orthopaedic surgery in the UK will allow considerably more opportunity for specialist training in spinal surgery.

There appears to be a need for four levels of such training. All general orthopaedic surgeons should be able to treat simple spinal problems, and to recognise more important and major conditions for onward referral. Some general consultants should have a special interest in spinal surgery, and perform disproportionately more spinal work. The third level is the spinal surgeon with a major subspecialist interest performing nearly all his work in the spinal field, but perhaps doing a share of trauma management in general. Finally, only fully specialist spinal surgeons should carry out complex spinal surgery, including the treatment of scoliosis.

The first level requires basic exposure to spinal surgery during the four-year training period, especially in the first three years, before the Intercollegiate Examination. The second-level surgeon should have a minimum period of a year in spinal surgery, not necessarily at the same surgical centre. At the third level, additional training would be in a teaching hospital centre with a major spinal interest, after the Intercollegiate Examination, with an additional six months in a scoliosis centre. A fourth-level spinal surgeon would need training to Intercollegiate level, followed by a six-month spinal module, partly in a neurosurgical unit by reciprocal arrangement.

This could be followed by a year of specialist scoliosis training at another regional centre. An overseas secondment should be encouraged.

At present, many senior registrar training programmes have enough flexibility to allow these changes to occur in training, but some have become repetitive. Careful analysis of training programmes is essential to allow proper sub- 
specialisation, not only in spinal surgery in general, but in scoliosis in particular.

P. BLISS, JP, FRCS

President, British Scoliosis Society

Little Court

College Road

Bath.

Crockard HA. Editorial: Training spinal surgeons. J Bone Joint Surg [Br] 1992;74-B:174-5.

\section{PRESSURE UNDER THE FOOT}

Sir,

It was interesting to read the article by Bransby-Zachary, Stother and Wilkinson on 'Peak pressures in the forefoot' in the July 1990 issue $(1990 ; 72-B: 718-21)$.

I would like to point out that the instrumentation system used by the authors to measure the peak pressures beneath the foot (Entran transducer) was originally designed to measure the pressures within the annulus of a vertebral spinal segment unit loaded to the point of fracture. These loads and pressures are very high, and the system is not suitable for measuring pressures under the foot.

I am, however, able to provide graphs of the forces measured under different regions of the normal foot by a load cell as described by Ranu (1986). Figure 1 shows the force-time history under the heel, Figure 2 shows it under the first metatarsal and Figure 3 under the hallux. It would be of interest to compare these forces with those shown by the system used by the authors, and also the pressure-time integral index. Figure 1 clearly shows the heel transient: this is a good measure of the frequency response of the load cell.

H. S. SINGH, PhD

Department of Biomechanics

New York College of Osteopathic Medicine

New York Institute of Technology

New York, USA.

Bransby-Zachary MAP, Stother IG, Wilkinson RW. Peak pressures in the forefoot. J Bone Joint Surg [Br] 1990;72-B:718-21.

Ranu HS. Miniature load cells for the measurement of foot-ground reaction forces and centre of foot pressure during gait. $J$ Biomed Engn 1986;8:175-7.

\section{ARTHROSCOPIC LAVAGE OF OSTEOARTHRITIC KNEES}

Sir,

Lest any of your readers should interpret the data from 'Arthroscopic lavage of osteoarthritic knees' by Livesley et al (1991;73-B:922-6) as offering convincing support for a policy of routine joint lavage in painful osteoarthritis of the knee, we write to draw attention to some methodological shortcomings of this study.

The study was described as 'controlled', but was not randomised. Rather, the allocation was determined on the basis of the surgeon to whom each patient was referred. This is not a trivial criticism; there is abundant evidence that bias may occur in such circumstances (Pocock 1983). There are other potential signs of bias: the male:female ratio was quite different in the two groups; the authors state that there were differences between groups for stress pain, morning stiffness, swelling and effusion; and it is not clear whether the two groups were matched at entry for pain, the principal outcome of interest. A number of validated pain-scoring systems are available. Why were they not used? Also, without a blinded assessment of pain, the validity of the measurements may be questioned.

After allocation to a treatment group, results should be analysed according to 'intention to treat'. Removing cases from the lavage group because of treatable lesions is unacceptable. How many 'treatable lesions' were present in the group who had physiotherapy alone?

Measurements (except for duration of stiffness) were made using categorical scales, some of which may have been ordinal; a number of variables appear to be dichotomous (warmth, stress pain, wasting, crepitus, sleep disturbance, swelling) although this is not stated clearly in the text. Thus the methods used for analysis and presentation are unsuitable as they apply to the analysis of continuous variables. Proportions of patients falling into each category and chisquared tests or tests for trend for the ordinal variables would have been more appropriate and more informative. It is also true that the large number of statistical comparisons performed (within groups and between groups) will lead to some small p-values by chance alone; more appropriate methods are available for the analysis of repeated measures data.

Finally, in Table $\mathrm{V}$ the authors compare average pain scores'. These may not be appropriately analysed by the Mann-Whitney $U$ test for a scale ranging from 0 to 3 . The

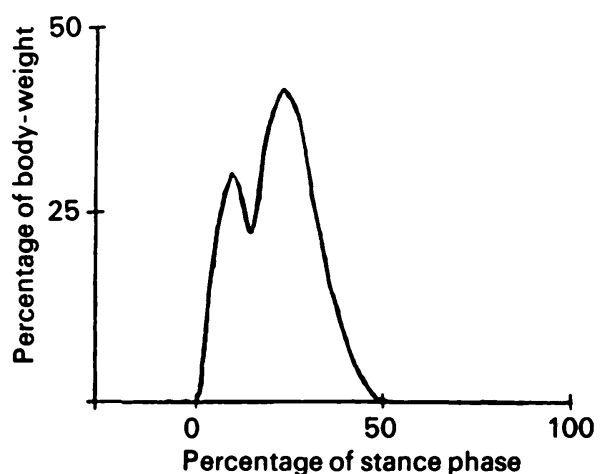

Fig. 1

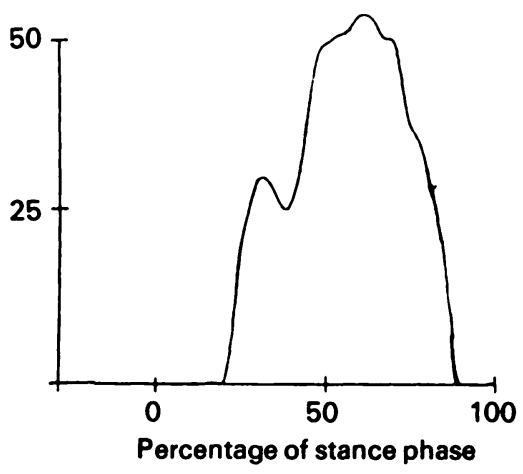

Fig. 2

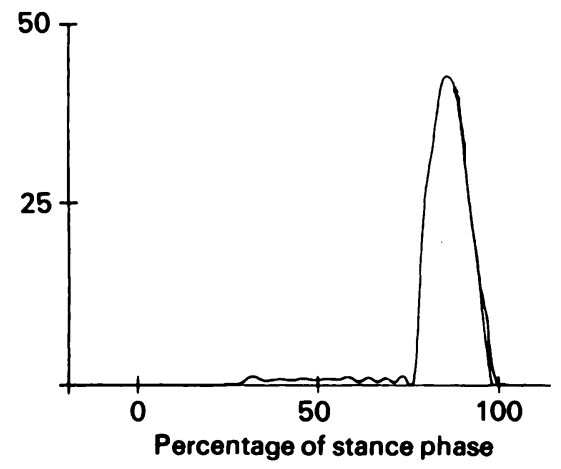

Fig. 3

Heel.

First metatarsal.

Hallux. 